\title{
Anaesthesia for Cleft Lip and Palate Surgery: Study from a Hospital of Eastern Nepal
}

\author{
Karki SB, ${ }^{1^{*}}$ Rajbanshi LK, ${ }^{2}$ Ariyal Batsalya, ${ }^{2}$ Shrestha $K^{3}$
}

\section{Affiliation:}

1. Consultant Anaesthesiologist, Department of Anaesthesia and Intensive Care, Birat Medical College \& Teaching Hospital, Biratnagar, Nepal

2 Lecturer, Department of Anaesthesia and Intensive Care, Birat Medical College \& Teaching Hospital, Biratnagar, Nepal

3. Regional Co-ordinator, Phect Nepal, Resurge International Surgical Outreach Programme

\section{A RT I CLE INFO}

\section{Article History}

Received : 15 Jan, 2017

Accepted : 27 April, 2017

Published : 30 April, 2016

(C) Authors retain copyright and grant the journal right of first publication with the work simultaneously licensed under Creative Commons Attribution License CC - BY 4.0 that allows others to share the work with an acknowledgment of the work's authorship and initial publication in this journal.

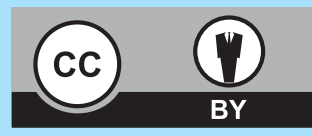

ORA 19

\section{* Corresponding Author}

Dr. Shambhu Bahadur Karki

Consultant Anaesthesiologist

Department of Anaesthesia and Intensive Care

Birat Medical College \& Teaching Hospital

Biratnagar, Nepal

Email: karkisb@yahoo.com

\section{Citation}

Karki SB, Rajbanshi LK, Ariyal Batsalya, Shrestha K. Anesthesia for Cleft Lip and Palate Surgery: Study from a Hospital of Eastern Nepal. BJHS 2017; 2 (1) 2 : 127-133.

\section{ABSTRACT}

\section{Introduction}

Cleft lip and palate deformity is the most common congenital birth defect caused by complex genetic and environmental factors. Perioperative management of these patients is always challenging and anesthesia has a great role for the surgery.

\section{Objective}

The aim of this study is to evaluate the outcomes including pre-operative selection of cases, intra-operative and postoperative complications in pediatric patients.

\section{Methodology}

This is retrospective study conducted on cleft lip and palate repair patients between the ages of 3 months to 12 years, operated under general anesthesia during last six years at Morang Co-operative Hospital, Biratnagar, Nepal. Total 570 patients were assessed with preoperative, intraoperative and postoperative parameters, complications and managements. The MSExcel office andSPSS software was used to analyze the data.

\section{Results}

Among 570 patients about one third came from the high mountain and hilly region and the rest from the Tarai. The maximum travel time to reach the hospital was 2 days. The percentage of cancellation was $22.13 \%$ and was mainly due to the respiratory problems. Among 570 patients 352(61.75\%) were males. While classifying the cases, 202 cases were presented with only cleft lip, 325 cleft lip and palate combined and 43 patients with isolated cleft palate. Narcotics were not used for analgesia and analgesia maintained with other measures. There was no intra and post-operative death and none of the patient received intra-operative blood transfusion.

\section{Conclusion}

Cleft lip and palate surgery in pediatric patients is possible in any hospitals when trained man power and proper operating and post-operative setup is available. Anesthesia for cleft lip and palate is challenging associated with several complications requiring continuous and vigilant anesthetic supervision and management for the better outcome.

\section{KEY WORDS}

Anaesthesia, cleft lip and palate, pediatric surgery 


\section{INTRODUCTION}

Orofacial clefts (OFC) are the most common congenital birth defect of lip, palate, or bothcaused by complex genetic and environmental factors. ${ }^{1,2}$ It occurs due to the failure of fusion or break in fusion of nasal and maxillary processes with the palatine shelves, which form during $8^{\text {th }}$ week of the embryonic period. ${ }^{3}$ Orofacial clefts present as part of the phenotype in over 600 specific genetic syndromes, more commonly in association with isolated cleft palate. ${ }^{4}$ Smoking, vitamins and folic acid deficiencies, alcohol consumption and use of non-prescription medication by pregnant women are predisposing environmental factors of orofacial clefts. ${ }^{5}$ Early repair is more important for the outcome of surgery and according to American Cleft Palate Association guidelines, cleft lip should be repaired within 6 months of age and cleft palate within 18 months. ${ }^{6}$ This centre has special cleft clinic established by the national NGO Phect Nepal and operating since 1999.

Oral-facial clefts are a major public health problem and the global average for the number of people born with cleft is about 1 in every 500 to 750 live births and every three minutes a child is born with a cleft lip or cleft palate ${ }^{1}$ and isolated cleft palate seen in 1 in 2000 live births. ${ }^{3}$ Cleft lip with or without cleft palate reported more in the males but isolated cleft palate seen more in females. ${ }^{7}$ There is a wide variation in the occurrence of clefts among different ethnic groups. In USA, Asian and Native American populations have prevalence rate of 2 per 1000, Europeans have 1 in 1,000 , and African-derived populations have about 1 in $2,500 .^{8}$ Das et al stated that Asians have the highest risk 1.4: 1,000 births followed by whites 1: 1,000 births and African Americans $0.4: 1,000$ births. $^{9}$ In SAARC countries India has the incidence of 1.4 per 1000 live births according to the survey of Indian health ministry in $2010 .^{10}$ In Pakisthan the prevelance rate is 1.91 per 1000 live births ${ }^{11}$ and in Nepal the accepted prevalence rate is 1.64 per 1000 live birth. ${ }^{6}$

Orofacial clefts might be syndromic if accompanied by additional structural abnormalities and nonsyndromic if they occur in isolation without other apparent abnormalities. About $70 \%$ of cleft lip with or without palate are non syndromic. ${ }^{12}$ Syndromes are more frequent in patients with cleft lip and palate (32\%) than in patients with cleft lip alone $(11 \%)$ or patients with cleft palate alone $(22 \%)$ in Indian patients. ${ }^{13}$ About 150 syndromes may be associated with cleft deformities. The most well-known are the Pierre Robin's, Treacher Collins and Goldenhar syndrome. Congenital heart disease occurs in $5-10 \%$ of these patients. ${ }^{14}$

The breakdown for the types of clefts is approximately 45 percent cleft lip and palate, 35 percent cleft lip, and 20 percent Cleft palate. ${ }^{15} \mathrm{Cleft}$ lip has a male to female ratio of about 2:1, and male to female ratio reported is $1: 2$ in isolated cleft palate. ${ }^{10}$ Unilateral Cleft lip is more common than bilateral, and for patients with unilateral Cleft lip, there is a 2:1 ratio of left to right sided clefts. ${ }^{8}$

Affected children have a range of problems including feeding difficulties due to problems with oral seal, swallowing and nasal regurgitation, poor dental development and other associated problems like hearing difficulties due to abnormalities in the palatal musculature, and speech difficulties due to nasal escape and articulation problems. Thus, clefts have a prolonged, adverse influence on the health and social integration of affected individuals. ${ }^{16}$

In 2008, the World Health Organization (WHO) has recognized that non-communicable diseases, including birth defects cause significant infant mortality and childhood morbidity and have included cleft lip and palate in their Global Burden of Disease (GBD) initiative. ${ }^{2}$

Perioperative management of patients can be challenging in resource limited country like Nepal. These patients often presents with airway problem making it crucial job during anaesthesia. The other associated congenital anomalies can alter the anaesthetic management. Till now there is no literature from Nepal defining demographic, clinical profile and intraoperative challenges and hence this study can be a milestone for the intraoperative management of patients with cleft disorder.

\section{MATHODOLOGY}

Total 570 children were analyzed between the ages of 3 months to 12 years of age operated at Morang co-operative hospital from Jan 2010 to Dec 2015. The electronic recording was started in this hospital from 2010 and this is a retrospective record analysis of all the details of patients operated after 2010. Study started after getting approval from the hospital authority. In this Centre cleft lip is operated from the age of 3 months and palate from 10 months.

\section{Inclusion criteria}

Patients with cleft lip with or without cleft palate and isolated cleft palate from 3 months of age to 12 years with ASA I and II physical status.

\section{Exclusion criteria}

1. Children above 12 years and below 3 months of age

2. Patients with other congenital anomalies like congenital heart disease, duodenal atresia etc.

All the collected patients were taken for the preoperative evaluation by surgeon, pediatrician and anesthesiologist and suitable babies were admitted for the preparation of surgery. During admission detailed discussion done regularly with the parents about the surgery, anesthesia, outcomes, risks and follow ups and get the informed consent for surgery. Routine 
preoperative evaluation and basic investigations including complete blood count, chest $x$-ray, urine analysis, height and weight measurements done to evaluate the babies and after getting all reports, set a plan for the surgery. No preoperative sedative premedication given and routine preoperative fasting guidelines instituted for preparation.

At the day of surgery IV line was opened at the preoperative room just before the surgery or directly at the operation room with 22/24G IV canula. Anesthesia management depends upon the types of the defect of the baby. Two types of anesthetic management applied including general anesthesia(GA) with endotracheal intubation and total intravenous anesthesia(TIVA). TIVA was used for the management of children with unilateral incomplete cleft lip with the age of two years or above and rest of the patients operated under GA. All patients received IV preoperative sedation of inj atropine $(0.02 \mathrm{mg} / \mathrm{kg})$ not less than $0.1 \mathrm{mg}$ and inj midazolam $(0.05 \mathrm{mg} / \mathrm{kg})$ at the operation table. The intraoperative monitoring included ECG, pulse oxymetry, noninvasive blood pressure(NIBP), temperature and a precordial stethoscope. To manage the heat lost the temperature of operating room was adjusted within $23-25^{\circ} \mathrm{C}$ along with warm blankets and caps to cover the baby. Out of 570 patients 539 operated under general anesthesia with endotracheal intubation and rest 31 babies under total intravenous anesthesia(TIVA). Intraoperative fluid used in this centre for babies was Isolyte $P$ which is a solution of $5 \%$ dextrose with $0.3 \%$ NS, Magnesium and potassium. Calculation of fasting and intraoperative fluid requirement calculated according to the 4-2-1 rule.

All babies induced with IV ketamine $(2 \mathrm{mg} / \mathrm{kg})$ and Propofol up to the $2-3 \mathrm{mg} / \mathrm{kg}$ and after testing the eye lid reflex the anesthesia mask was applied with oxygen and halothane. After successful ventilation, succinyl choline $(2 \mathrm{mg} / \mathrm{kg})$ given to facilitate intubation. When muscle relaxation was adequate laryngoscopy was performed using Macintosh blade and preformed south facing RAE endotracheal tubes were used for intubation and the tube is fixed properly at the centre. During laryngoscopy, external laryngeal compression was used routinely for better visualization of larynx. No of attempts for successful laryngoscopy and intubation recorded and discussed in results. Long acting muscle relaxation Inj vecuroneum $0.1 \mathrm{mg} / \mathrm{kg} \mathrm{IV}$ used in some cases if required. inj tramadol $1 \mathrm{mg} / \mathrm{kg}$ intravenously used for analgesia. The circuit used in this center was Meplesan D in all cases. Anesthesia was maintained by $100 \%$ Oxygen and $0.75-1.5 \%$ halothane. For TIVA group after inj atropine and inj midazolam, intermittent dose of inj ketamine and propofol used with bilateral infraorbital block. The additional analgesia in all cases also provided by surgeons during administration of inj xylocaine with adrenalin in the operative field. In this centre the strength of Inj adrenalin with xylocaine used is 1: 100000 prepared after mixing with $0.5 \%$ bupivacaine to prolong the analgesia in postoperative period. The average requirement of dose of the adrenaline for the infiltration was 3-5 ml (30-50 microgram) in cleft lip cases and 12-15 ml (120-150 microgram) in cleft palate cases. Halothane was stopped always during the infiltration of adrenalin and anesthesia was maintained with inj ketamine and inj propofol to prevent the halothane induced cardiac arrhythmias. Broadspectrum antibiotic used intravenously for all babies before surgical incision.

At the end of the procedure residual neuromuscular block was reversed using inj neostigmine if it was used during surgery. In this centre both deep and awake extubation method is used depending upon the conditions. Easily intubated cases planned for deep extubation if the baby remains quite with adequate rate and depth or respiration at the end of surgery. Extubated babies were watched carefully and if all the parameters were normal then the babies placed on the lateral position with all monitors attached in operating room till the babies fully revived. The awake extubation plan applied to all difficult intubation babies and those babies who fight at the end of surgery even without decreasing the depth of anesthesia. Throat was routinely checked at the end of the procedure to confirm the removal of the throat pack and to observe clots and any foreign bodies and ongoing bleeding before extubation. Babies were transferred to the postoperative room when they fully awake and start to cry. In some cases when there was preoperative snoring or prolong postoperative airway obstruction, a tongue stitch is placed which pulls the tongue forward and clear the airway and prevent from postoperative airway obstruction. Close observation required for these cases into the recovery period. Once the child was fully awake, no bleeding from the wound and no crying then feeding with the clear fluid begins. No regular IV fluids given to the babies in the postoperative period and IV infusion prescribed only if the babies were not able to take fluids orally.

Appropriate analgesia is very important among the babies too and for postoperative analgesia intrarectal paracetamol $(10-15 \mathrm{mg} / \mathrm{kg})$ used routinely at the end of the surgery. Once the babies able to drink they were prescribed with the suspension of paracetamol and ibuprofen orally. All intraoperative and postoperative complications were recorded properly. All the collected data was entered in MS Excell andanalysed by SPSS. For the data analysis all babies were grouped into the four groups: 3 months -2 years, 2 - 5 years, 5-9 years and 9-12 years.

\section{RESULTS}

During the six years of the study period, Centre have operated 570 facial cleft cases with the age of 3 months to 12 years under general anesthesia. The details of age, sex and types of cleft are given in the table 1 and 2 . 
Table 1: Demographic profile and anaesthetic techniques

\begin{tabular}{|c|c|c|c|c|c|c|}
\hline \multirow{2}{*}{ Age } & $\begin{array}{c}\text { Number and } \\
\text { Percentage } \\
\text { of patients }\end{array}$ & \multicolumn{2}{|c|}{ Sex } & \multicolumn{2}{|c|}{$\begin{array}{c}\text { Anaesthetic } \\
\text { Technique }\end{array}$} \\
\cline { 5 - 7 } & Male & Female & GA & TIVA \\
\hline $\begin{array}{c}\text { 3 months } \\
\text { 2 yrs }\end{array}$ & $169(29.64 \%)$ & 117 & 52 & 167 & 2 \\
\hline 2-5 yrs & $342(60.00 \%)$ & 199 & 143 & 319 & 23 \\
\hline $5-9$ yrs & $47(8.24 \%)$ & 31 & 16 & 41 & 6 \\
\hline 9-12yrs & $12(2.10 \%)$ & 5 & 7 & 12 & 0 \\
\hline
\end{tabular}

Among the operated babies 208 (36.50\%) were from the high mountain and hilly regions and rest 362(63.50\%) from Tarai. Patients required few hours to two days to reach the hospital.

Out of 570 cases only 31 (5.43\%) babies operated under TIVA and rest under GA with endotracheal intubation. This study shows that the prevalence of orofacial cleft was the male dominated and among them 352 babies (61.75\%) were males. While observing the types, 202 babies (35.43\%) were with cleft lip only, 43 (7.54\%) babies with cleft palate only and 325 (57.01\%) with cleft lip and palate combined. About the procedure 386 (67.71\%) babies were operated for cleft lip and rest 184 (32.28\%) for cleft palate. Out of 732 babies $162(22.13 \%)$ cancelled and rest admitted for the surgery. The most common medical condition causing cancellation was Acute Respiratory Infection 137(18.71\%), Malnutrition 21 $(2.86 \%)$, no consent $1(0.17 \%)$, and surgical site skin infection $3(0.52 \%)$.

\section{Table 2: Types of deformity}

\begin{tabular}{|l|c|c|c|c|}
\hline $\begin{array}{l}\text { Facial } \\
\text { deformity }\end{array}$ & $\begin{array}{l}\text { Frequencies } \\
\text { (N 570) }\end{array}$ & Percentage & \multicolumn{2}{|c|}{ Sex } \\
\hline \begin{tabular}{l|l|l|} 
Cleft lip \\
only
\end{tabular} & 202 & $34.43 \%$ & 123 & 79 \\
\hline $\begin{array}{l}\text { Cleft } \\
\text { palate } \\
\text { only }\end{array}$ & 43 & $7.54 \%$ & 17 & 26 \\
\hline $\begin{array}{l}\text { Cleft lip } \\
\text { and palate }\end{array}$ & 325 & $57.01 \%$ & 209 & 116 \\
\hline
\end{tabular}

Out of 570 surgeries 109 patients had intra operative complications, among them $84(14.73 \%)$ had minor complication and 25(4.38\%) had major (table 3). Tachycardia seen in 47 patients and was the most common minor complication seen followed by hypoxia $(n=39)$ and hypothermia $(n=26)$.
Figure 1: Causes of cancellation

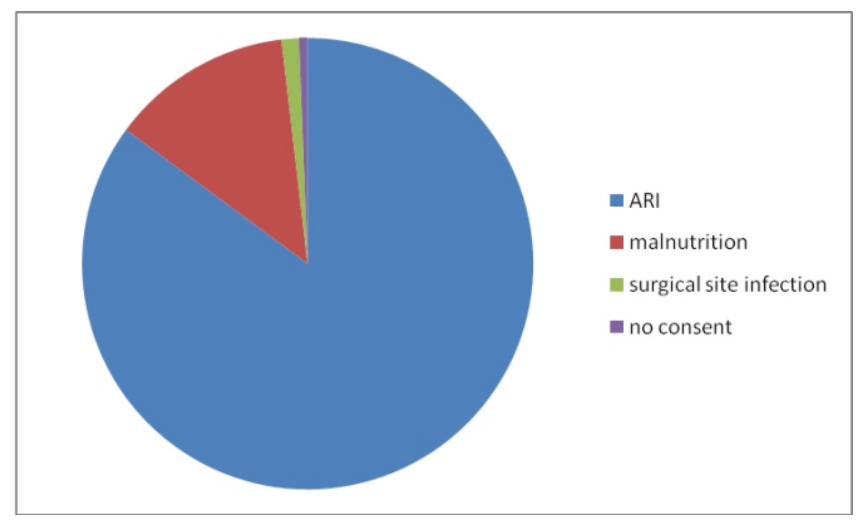

Ventricular extrasystoles seen in 23 patients during administration of inj xylacaine with adrenalin and 2 patients developed bradycardia after extubation. Difficult intubation was defined if laryngoscopic attempt was more than two times ${ }^{17}$ and difficult intubation seen in 21 patients in this study. One patient was cancelled due to failed intubation and referred to our Kathmandu centre. Endotracheal tube compression seen in 4 cases due to the tight placement of the retractor. Laryngospasm was seen in 5 cases which were managed by inj succinyl choline and positive pressure ventilation. Bronchospasm was seen in 8 cases. Respiratory obstruction seen more frequently after extubation and seen in 37 cases and postextubation coughing was seen in 23 patients.

\section{Figure 2: Frequency of intraoperative respiratory complications}

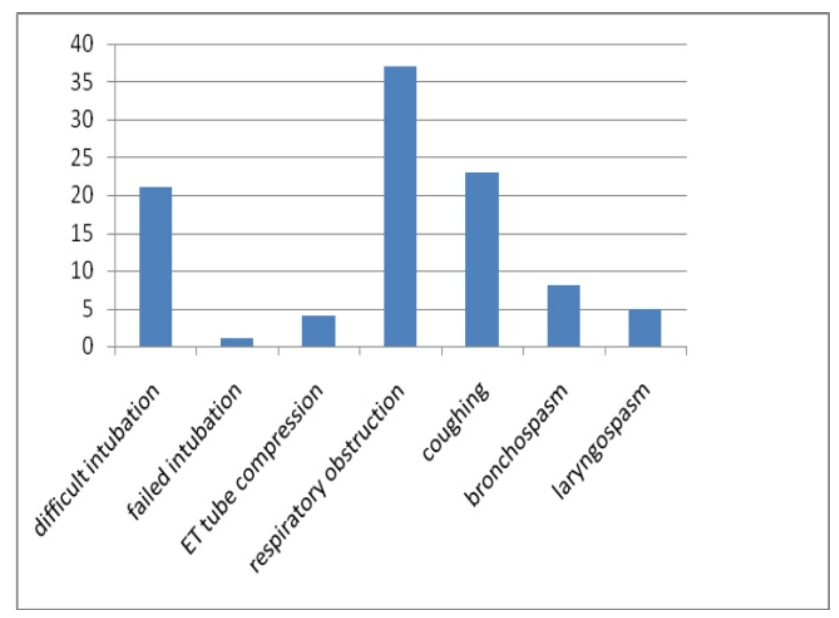

In postoperative period, 1 cleft lip patient developed hematoma after injury and 9 cleft palate patients had postoperative wound bleeding on the same day of surgery. None of the patients required intraoperative and postoperative blood transfusion.

No ketamine related hallucinations seen in the postoperative period. 
Table 3: Intra operative complications

\begin{tabular}{|lcc|}
\hline Complications & Number of Patients & Percentage \\
\hline Difficult intubation & 21 & $3.86 \%$ \\
\hline Failed intubation & 1 & $0.17 \%$ \\
\hline Tube compression & 4 & $0.70 \%$ \\
\hline Hypoxia & 39 & $6.84 \%$ \\
\hline Tachycardia & 47 & $8.24 \%$ \\
\hline Bradycardia & 2 & $0.35 \%$ \\
\hline PVCs & 23 & $4.03 \%$ \\
\hline Hypothermia & 26 & $4.56 \%$ \\
\hline Laryngospasm & 5 & $0.87 \%$ \\
\hline Bronchospasm & 8 & $1.40 \%$ \\
\hline Upper airway obstruction & 37 & $6.49 \%$ \\
\hline Post extubation coughing & 23 & $4.03 \%$ \\
\hline
\end{tabular}

\section{DISCUSSION}

Roldan et al published an article "ten-Year cleft Surgery in Nepal" in 2016 and reported that patients were travelling from several parts of the country, taking up to 5 days to reach the hospital. ${ }^{18}$ Patient selections during preoperative evaluation are very important for the safety of anesthesia in cleft surgery. $^{19}$ Out of 732 registered cases $162(22.13 \%)$ werecancelled and the leading cause of cancellation was ARI which constituted $137(18.71 \%)$ patients. In a study of Roldan et al the cancelation rate was $30.9 \%$ due to several causes. ${ }^{18}$ The incidence of ARI in developing country is about $20 \%$ and the incidence is much higher in cleft patients due to the anatomical abnormality of the air passage and the attack rate of ARI decreased with increasing age of the children. ${ }^{20,21}$ Incidence of ARI in children up to $10 \mathrm{yrs}$ of age is 5.9 per child per year with the duration of 7-10 days of active symptoms and the residual pulmonary effect remains up to the 6 weeks so the anesthesiologist should be more conscious to find a safe window period of surgery for the cleft children. ${ }^{22,23}$ Why patients with ARI should be cancelled and called after 6 weeks because use of endotracheal tube in a child with ARI increases the risk of adverse respiratory events by 11 fold and only children with the mild symptoms of ARI can go for surgery if endotracheal intubation is not required. ${ }^{23}$

Ideally cleft lip should be repaired within the 6 months of age and cleft palate before the development of speech or $2 \mathrm{yrs}^{24}$ According to the guidelines of this centre, cleft lip is repaired after 3 months of age and at least $5 \mathrm{~kg}$ of weight and cleft palate after 10 months of age $10 \mathrm{~kg}$ of weight and hemoglobin $10 \mathrm{gm} / \mathrm{dl}$. Among 570 cleft surgeries 347 (60.87\%) were between $2-5$ years of age and about $10 \%$ cases above 5 years of age, so only $30 \%$ babies appears for the surgery at the age of below 2 years. This late presentation was mainly due to the unaware of availability of the service. Richard et al also reported about the cause of the late presentation of patients for the cleft surgery in Pokhara, Nepal and found that $31 \%$ cause was unaware of the availability of the service. ${ }^{25}$ In Nigeria only $40 \%$ babies came for the cleft surgery before the age of 1 year. ${ }^{26}$

During the 6 years of the study period, there was no death occurred and no any child referred to the higher Centre due to postoperative complications. One patient canceled due to failed intubation and send to Kathmandu cleft centre. In the study of large no of cases Triet et al reported 1 death in 40240 cases and Fisher et al reported 4 deaths in a large voluntary surgery program. ${ }^{3}$

Patients with orofacial clefts are usually associated with abnormal dentition, malnutrition and repeated ARI and the risk of repeated $A R I$ increased because of feeding difficulties. ${ }^{21,27}$ In this study 21(2.86) patients cancelled due to malnutrition, 4 of them got admitted to the nutrition centre of the government hospital and rest sent to their home with essential advise.According to the report of Roldan et al $18(1.72 \%)$ patients cancelled due to low weight in a charity hospital of Nepal. ${ }^{18}$

Difficult intubation is known to be a main factor in deaths associated with anesthesia in surgical patients. ${ }^{28}$ In our study total 21 (3.68\%) cases recorded as a difficult intubation and 1 case of failed intubation. In the study of Xue et al $^{28}$ difficult intubation was seen in $4.77 \%$ cases and Gunawardana reported $7.38 \%$ of difficult intubation and difficult intubation rates decreased with the increase in the age of the babies. ${ }^{17}$ Difficult intubation rate was 11.14 in infants less than 6 months of age, $7.05 \%$ in the age group $6-12$ months, $4.12 \%$ in 1-5 years olds and laryngoscopy is not difficult in babies more than 5 years of age. ${ }^{17}$

Anesthesia for cleft lip and palate surgery carries high risk of adverse respiratory events, such events reported by Adenekan et al was $5 \%{ }^{26}$ and Penam et alan incidence of $10 \%{ }^{29}$. The frequency of intraoperative respiratory complications reported by Kulkarni et alwas $2.4 \%$ in cleft lip and $8.7 \%$ in cleft palate repair. ${ }^{27}$ Adverse respiratory events occur usually during intubation and extubation but were seen more frequently immediately after tracheal extubation than during induction of anesthesia. ${ }^{29}$ The most commonly seen respiratory adverse events in our study were respiratory obstruction and coughing but as severe complications laryngospasm and desaturation also occurred more after the extubation. Coughing itself is usually not a complication, it is a physiological response to protect the airway from aspiration. ${ }^{29}$ However, coughing may increase blood pressure, heart rate and persistent coughing might be associated with 
other complications like salivation, airway obstruction, wound bleeding, desaturation and laryngospasm. ${ }^{29}$ The risk of perioperative respiratory adverse events is less if muscle relaxation used for tracheal intubation. ${ }^{30}$ There were no cases of difficult ventilation after induction of anesthesia in this study and Inj succinyl choline given only after successful manual ventilation of lungs. In the present study, 97 (17.71\%) patients developed respiratory complications. Respiratory complications seen more frequently in cleft palate surgery than the cleft lip repair. Brindha et al reported $0.4 \%$ perioperative respiratory complication in cleft lip repair and $12 \%$ in cleft palate repair ${ }^{31}$ and in a study of 50 cleft children by Desalu et al $38 \%$ patients developed respiratory complications. ${ }^{32}$ More conscious the patient is on arrival at the recovery room, the lower the incidence of respiratory complications $^{33}$ and the anesthesiologist is fully responsible for the care of the patients from induction of anesthesia to full recovery. ${ }^{34}$ In this centre extubated babies were always kept in operating room till the child fully recovered.

Hypothermia is defined as a core temperature below $36^{\circ} \mathrm{C}$ and it is also one of the most common perioperative disturbance in pediatric patients and the incidence of hypothermia can be up to $20 \%$ in major surgical pediatric patents. ${ }^{35}$ In a study done by Brinda et al the occurrence of hypothermia was $3.1 \%$ and was due to the prolong operation time and therefore shortening of duration of surgery is quite important to prevent hypothermia. ${ }^{31}$ In thisstudy $26(4.56 \%)$ patients developed hypothermia during surgery.

In cleft surgery surgeons are using high concentration of adrenaline to achieve a blood less field and in this study the concentration of adrenaline used was 1: 100000. The solution of adrenaline used in cleft lip was 2-5 $\mathrm{ml}$ and for the cleft palate $10-15 \mathrm{ml}$ only. Cardiac arrhythmia is closely related with the use of vasopressor with halothane and in the finding of Hirshom et al ventricular arrhythmias occurred quite frequently in halothane anesthetized patients when a small amount of adrenaline was injected. ${ }^{36}$ For the prevention of such arrhythmias author has suggested to use the lowest concentration of halothane, use of concentration of adrenaline at $1: 100000$ or 1:200000 strength, injection of vasopressor periodically and avoid combined use of halothane and vasopressors and regular use of ECG monitor for anesthesia. ${ }^{36}$ The concentration of adrenalin used in this centre is $1: 100000$ and for the prevention of complications, the adrenalin solution is injecting in the operation site periodically and always after discontinuation of the halothane. During injection of vasopressor,anesthesia is maintained with intravenous propofol and ketamine. Criteria of tachycardia in this study were $50 \%$ rise in the heart rate than the base line and bradycardia if the heart rate was less than 80 beats per minute. In this study 47 patients developed tachycardia 2 cases developed bradycardia after extubation andventricular extrasystoles seen in 23 patients. So the total cardiovascular complication seen in this study was in $72(12.63 \%)$ patients.

\section{CONCLUSION}

Anesthesia for the cleft lip and palate surgery in infants and children is always carries a great challenge to the anesthesiologist due to the number of perioperative complications. Anesthetic management of the operative team must have skilled and experienced medical persons, appropriate intra and postoperative monitoring equipments, essential airway devices and advanced postoperative care set up to minimize the complications.

\section{CONFLICT OF INTEREST}

The authors declare no financial support or conflict of interest.

8. Dixon MJ1, Marazita ML, Beaty TH, Murray JC. Cleft lip and palate: Understanding genetic and environmental influences. Nat Rev Genetics. 2011 Mar;12(3):167-78.

9. S. K. Das, R. S. Runnels, J. C. Smith, and H. H. P. Cohly, "Epidemiology of cleft lip and cleft palate in Mississippi," Southern Medical Journal, vol. 88 , no. 4, pp. 437-442, 1995

10. Ellery Ward, Dr Azim Khan, Dr Abey John, Cleft Lip and Palate in India; ISP collection, Paper 1818; Spring 2014

11. Elahi MM, Jackson IT, Elahi O, Khan AH, Mubarak F, Tariq GB, et al. Epidemiology of cleft lip and cleft palate in Pakistan. Otolaryngol Clin North Am 2007; 40:27-60.

12. Stainier P, Moore GE, Genetics of cleft lip and palate: Syndromic genes contribute to the incidence of non syndromic clefts. Hum Mol Genet 2004; 13 (1): 73-81

13. Venkatesh R.Syndromes and anomalies associated with cleft; Indian J Plast Surg.2009 Oct; 42(Suppl): 51-55.

7. Agbenorku P. Orofacial Clefts: A Worldwide Review of the Problem, ISRN Plastic Surgery Volume 2013 (2013), Article ID 348465, 7 pages 
14. Liang CD1, Huang SC, Lai JP A survey of congenital heart disease in patients with oral clefts.Acta Paediatr Taiwan. 1999 Nov-Dec; 40(6):414-7.

15. Gayatri Moghe, Simratvir Mauli, Abi Thomas, Vijay A.E.Bridging the Gap: Addressing Challenges Toward Improvement of Clef Teamwork in a Tertiary Care Center in North India: A Pilot Study, The Cleft PalateCraniofacial Journal 50(4) pp. 473-480 July 2013

16. B. J. Leonard and J. D. Brust, "Self-concept of children and adolescents with cleft lip and/or palate," Cleft Palate-Craniofacial Journal, vol. 28, no. 4, pp. 347-353, 1991.

17. Gunawardana.Difficult laryngoscopy in cleft lip and palate surgery; British Journal of Anesthesia.1996;76: 757-759

18. Roldan J C, Pape H D, Koch H, Kollar M.Ten-Year Cleft Surgery in Nepal:Achievements and Lessons Learned for Better Cleft Care Abroad. last Reconstr surg open. 2016;4(5):e71

19. Tremlett M, Anesthesia for cleft lip and palatesurgery. Current Anesthesia Critical Care. 2006;15: 309-16.

20. Chatterjee S, A study of epidemiological factors related to Acute Respiratory Infection in under five; The internet journal $f$ medicine. 2006, volume 7, no:2

21. Olasoji HO, Dogo D. Experience of unoperated cleft lip and cleft palate in a Nigerian Teaching Hospital. Tropical Doc 2002; 32: 33-36

22. Anand Krishnan, Amarchand R. Epidemiology of ARI in childrenpreliminary result of a cohort in a rural north Indian community; BMC infectious Dis 2015; $15: 462$.

23. Kotur PF, Surgical repair of cleft lip and palate in children with URTI; Indian Journal of Anesthesia; 2006; 50 (1) :58-59.

24. Gupta K, Gupta P, Tyagi SK. Anesthetic management of Smile Train in a blessing for population of low socioeconomic status: A prospective study. Anesthe Essays Res. 2010Jul-Dec; 4 (2) : 81-84.
25. Richard S, Khadka SB. Reasons for late presentation of cleft deformity in Nepal. Cleft palate craniofacial journal, March 2004; 41 (2): 199-201.

26. Adenekan AT, Faponle AF et al. Perioperative adverse events in cleft lip and palate repair. SAJ Anesth Analg 2011;17(6):370-373

27. Kulkarni K, Patil M. Perioperative respiratory complications in cleft lip and palate repair;An audit of 1000 cases under Smile Train Project. IJA 2013, Nov-Dec 57 (6): 562-568

28. Xue FS, Zhang GH et al. The clinical observation of difficult laryngoscopy and difficultintubation in infants with cleft lip and palate. Pediatric anesthesia 2006; 16: 283-289.

29. Pena $\mathrm{M}$, Choi $\mathrm{S}$ et al. Perioperative airway complications following pharyngeal flappalatoplasty. Ann Otol Rhino Laryngo 2000;109: 806-811.

30. Hatch DJ, Airway management in cleft lip and palate surgery. BJA 1996; 76: 755-756

31. Brindha R, Sowmya SV et al. Perioperative and postoperative complications in cleft lip and palate surgeries; A retrospective analysis under Smile Train Project. Internat Joun of Curr Med and Applied Scinces, 2014; 5(1): 1-7

32. Desalu I, Adeyemo WL et al. Airway and respiratory complications in children undergoing cleft lip and palate repair. Ghana Medical Journal 2010; 44(1): 16-20.

33. Parr SM, Robinson BJ. Level of consciousness on arrival in the recovery room and the development of early respiratory morbidity, Anesthesia and intensive care. 1991; 19(3):369-372.

34. Taylor T, Postoperative recovery. Medical Protection Society Casebook 1996, No 7: 4-7

35. Bajba SJ, Swati. Perioperative hypothermia in pediatric patients: diagnosis, preventionand management. Anesthesia Pain and Intensive Care 2014; 18(1): 97-100

36. Pelkofski JJ. Cardiac arrhythmia in oral surgery: A literature review. Anesthesia progress. 1974; 21(5): 132-133 